\title{
Global Conflict Data: Introducing the World Handbook of Political Indicators IV
}

\author{
J. Craig Jenkins \\ Ohio State University \\ Charles L. Taylor \\ Virginia Tech University \\ Marianne Abbott \\ Thomas V. Maher \\ Ohio State University \\ Purdue University \\ Lindsey Peterson \\ Mississippi State University
}

\begin{abstract}
The World Handbook of Political Indicators IV (WHIV) provides global cross-national daily coverage of contentious politics events - protest, violence, sanctions and relaxations - conducted by governments, insurgents, and civilians. Using auto-coding of Reuters international newswire based on KnowledgeManager, ${ }^{\mathrm{TM}}$ the dataset covers 231 countries and territories from January 1 , 1990 through December 31, 2004 and includes 40 distinct event forms and a set of standard actors and targets resulting in 264,289 events. WHIV's breadth of geographic coverage, detailed atomic level event forms, and temporal specificity provides unique opportunities for studying contentious conflict globally and in specific countries. We discuss the uses of these data and the global distribution and trends in protest, political violence and governmental sanctions and relaxations.
\end{abstract}




\section{Global Conflict Data: Introducing the World Handbook of Political Indicators IV}

The use of political event data has exploded over the past two decades, as a result of new types of event data and methods for generating these data (Bernauer and Gleditsch 2012; Schrodt 2012). Recent event data projects have focused on episodic processes, such as the onset, lethality and duration of civil wars (Gleditsch et al. 2002), one-sided violence against civilians in civil wars (Eck and Hultman 2007), the behavior of states and other actors in international political crises (Wilkenfeld et al. 2010), and a combination of what we will call "atomic" level events and other discrete processes in civil war contexts (Raleigh et al. 2010). While this has generated a large literature on civil wars and related high-intensity armed conflict, it has left unaddressed other central questions, such as the driving forces behind low intensity protest and conflict, the impact of protest and political violence on democratization and political change, strategic decision-making in civil conflicts, factors influencing the selection of targets, and the dynamics of protest cycles and conflict escalation. Previous research focusing on these issues has typically focused on one country, movement or conflict at a time without considering how the processes listed above generalize or work differently across countries, regions, political regime types and the like. Addressing these questions requires a more comprehensive set of event data, including temporal data that can be integrated with non-contentious events. The World Handbook of Political Indicators IV (WHIV) dataset provides such a dataset by mapping a broad set of contentious politics events - including protest, violence, and governmental sanctions and relaxations - at the daily level with actor, target and location information in the tradition of the World Handbook of Social and Political Indicators (Taylor and Jodice 1983).

$W H I V$ is a discrete daily event data set at the atomic level, by which we mean events involving actors, targets and event forms extracted from news reports on a daily 24 hour clock 
basis. By atomic, we treat these events as the basic atoms of dyadic and multilateral political interactions as described in these news stories. WHIV is derived from machine-coding of the lead lines (first 250 words) of Reuters international newswire stories using the Virtual Research Associates Knowledge Manager ${ }^{\mathrm{TM}}$ parser. It includes 40 event forms and covers 231 countries, territories and world regions to identify 263,912 daily events between 1990 and 2004 . Over 95 percent of these events are intra-state, i.e. the actor and target have the same national or territorial location, but a significant share (almost 5 percent) involve transnational interactions (i.e. different national or territorial locations for actors and targets). Other than transnational terrorism, such transnational events are largely unstudied in existing literature. All events are based on a discrete 24 hour clock day, corresponding to the normal reporting cycle of international newswires. This means that extended campaigns and more complex processes (e.g. seizures of major territory) that typically require more than a day to transpire are represented in terms of discrete "single day" events as provided in newswire stories. The advantage of this event data approach is that one can study the interaction among temporally proximate events in detail using 24-hour time units. In addition to a daily event file, WHIV is also available from our website (https://sociology.osu.edu/worldhandbook) and DataVerse https://dataverse.org/) in an aggregated annual form and can be aggregated to fit other time units (e.g. weeks, months, quarters), specific actors, targets and/or locations. WHIV events are compatible with the larger IDEA event framework (Bond et al. 2003) ${ }^{1}$ and thus can be integrated with IDEA measures of non-contentious events. Less than $10 \%$ of the events in most newsfeed involve contentious events. Reuters international newswire has the advantage during the time period in question of being the world's largest English-language electronic newswire. It has consistent diction, grammar and reporting structure, making it a strong basis for auto-coding. 
This article first addresses the need for such a global contentious events data set. It then summarizes WHIV's coding procedures and features for studying contentious politics. Finally, we discuss global trends in protest, political violence, sanctions and relaxations during the time period of January 1, 1990 to December $31,2004 .^{2}$

\section{Why Contentious Event Data?}

The growth of electronic news and text archives accessible through the internet coupled with the development of new machine-based search and coding methods has fueled an explosive growth of new event data projects (see: O’Brien 2010; Schrodt 2012; footnote \#2 above). Recent data development has focused on particular countries or regions such as Africa (Raleigh et al. 2010; Salehyan et al. 2012), Northern Ireland (Loyle, Sullivan, and Davenport 2014), and the Middle East or "Levant" (Gerner et al. 1994; Schrodt and Gerner 1994), and critical issues such as water conflict (Bernauer et al. 2012; Gilmore et al. 2005), urban violence (Urdal and Hoelscher 2012), and anti-governmental protest and governmental instability (Banks and Wilson 2012). WHIV complements these efforts by providing global cross-national daily data on a broad range of contentious politics events. ${ }^{3}$

The key virtue of atomic event data is capturing the strategic interaction between groups. How else can one capture, for example, the decision by protestors to use violence to attack the government? Or the decision by authorities to use coercion or martial law to control protests? While one cannot directly tap the decision-making per se, one can obtain a useful set of proxy measures of strategic interaction based on news reports about contentious and other interactions. In conflict early warning research, such data are typically referred to as "dynamic" as opposed to structural measures (typically annual) that are often "too late" to provide useful early warning signal or aggregated to too coarse a time unit to be useful. 
WHIV provides daily contentious event data at the country/territory level for 1990 through 2004 (see list below). Based on the larger IDEA event framework (Bond et al. 2003), WHIV uses 40 event forms tapping a variety of protests, political violence, governmental sanctions, and governmental relaxation events. Beyond more generic "protests," one can examine seven forms of protest (demonstrations, marches, altruistic protest, obstructive protest, defacements, support rallies, and strikes/boycotts), and twenty types of coercion and violence (e.g. riots, hostage seizures, political arrests, RPG attacks, aerial assaults, and so on). Following the WEIS tradition (McClelland and Hoggard 1969), event forms are formally independent of actors, although many events are in terms of natural language anchored in specific actors (e.g. "relaxations" refer to governmental actors). This broad set of event forms is of particular use when examining strategic interactions in public contentions where one is examining shifts in strategy by the involved actors. These events can also be ordered in terms of intensity and used to construct indices of conflict processes such as Goldstein (1992) weights and conflict carrying capacity (Jenkins and Bond 2001). One can also focus on particular types of actors, targets, and specific country/territorial locations. These data allow one to address such questions as:

- What types of protest and violence are used by challengers against governments and other institutional actors (Tarrow 2004; Barrie and Ketchley 2018)?

- What tactics (e.g. nonviolent protest, violent attacks) are more effective in producing social and/or political change? Does protest contribute to democratization (Kadivar and Caren 2015; Kadivar, Usmani and Bradow 2017; Kadivar and Ketchley 2018;)?

- What are the responses of authorities to various protest tactics? Do these vary by democratic or non-democratic regimes, styles of political control, temporal 
sequence in conflict cycles, or other features of governmental legitimacy and institutions (Gilley 2006; Wada 2016; Underwood 2016; Costello 2018; Jenkins and Costello 2018)?

- Does harsh repression create a switch in protest tactics, e.g. from nonviolent to violent? Is this switch contingent on, e.g. identities of contenders, sequence in a conflict cycle, or the like (DeMerritt 2009; Rod and Weidmann 2013; Wada 2016)?

- Are human trafficking, refugee flights, other forms of crime, sexual violence, etc. linked to other types of violent civil conflict? How does political violence and other forms of contention affect economic growth and social disparities (Galster 2015)?

$W H I V$ provides temporal flexibility. One can use daily data, or aggregate to other time units such as weeks, months, quarters and years. WHIV data files are provided publicly in daily and annual forms. Temporal flexibility is a major advantage when for examining the time horizons and response capacities of various actors. Rasler (1996), for example, used weeks to find that coercive state repression was initially negative on protest but, after three or more weeks, had an accelerator (i.e. positive) effect. With two or three weeks to respond, Iranian opposition groups in her study regrouped, forged new ties and mobilized new protests. For other groups and settings, the timing sequence may be different. As Shellman (2004) demonstrates, temporal flexibility is critical to testing alternative ideas and may produce different results depending on temporal aggregation. Different protest groups have different levels of tactical flexibility. Recent research has shown that the timing of repression has different effects depending on whether it occurs in a context of rising or declining dissent (Sullivan, Loyle, and Davenport 
2012) and that closely timed action-reaction violence is more likely with ethnic groups that are being marginalized, in regions where poverty leaves few economic alternatives, and in urban areas where there is more robust communication networks associated with population and technology (Linke, Witmer, and O'Loughlin 2012). Using such flexibility in terms of timing allows one to make inferences about strategic calculations, such as military advantages versus retaliatory violence (Schneider, Bussmann, and Ruhe 2012).

\section{Features of WHIV Data}

WHIV is designed for the quantitative analysis of contentious dynamics, either by itself or in conjunction with other data. It is particularly well suited for global-comparative and time series analyses, using countries and territories as its geographic units. ${ }^{4}$ In the following, we discuss key features of the data and how they are coded.

Event Forms. Table 1 provides the 40 WHIV event forms along with their frequency in the larger 15-year global dataset. WHIV includes only contentious events, i.e. interactions that stand outside conventional political behavior and entail an element of negative sanction and uncertainty of response (Bond et al. 2003). We also include relaxations as signals of reduced contention. These data are extracted by machine-coding, using grammatical patterns to identify actor, event form, and target along with location information and other derived features. WHIV events are the contentious subset of the broader IDEA event framework (Bond et al. 2003) and, as such, can be integrated with non-contentious IDEA measures and other data. ${ }^{5}$ Events are grammatically identified by the parser, and then coded at the lowest possible level of specificity, creating a set of "cue" and "terminal level" events. For example, a protest demonstration (PDEM) is a cue category (a more general level of event form) for a reported action whose news description does not allow it to be classified at a more precise or terminal level (e.g. as protest 
obstruction, protest march, protest defacement, or protest altruism). Despite the overlap, cue and terminal level events are mutually exclusive in that they do not get coded in the affirmative simultaneously (see Table 1 for all cue and terminal event forms). ${ }^{6}$ In principle, event forms are unlimited as to actor, although in practice some event forms (e.g. political arrests, crowd control) are anchored in specific actors in natural language. Using the daily file allows the user to finetune the selection of relevant events.

(Table 1 about here)

The most common WHIV events are physical assaults, small arms attacks and raids. Support rallies are the most common protest event followed by strikes/boycotts while protest altruism (mostly hunger strikes) is the least common. WHIV includes some events not covered in other contentious events datasets, such as beatings and sexual assaults, which may not always be political in the sense of either motivation or targeting but meet the basic criteria of contentiousness and, in some broad sense, are political (i.e. power related). This opens up the possibility of studying with event data methods collective rapes such as in the Balkans and several African conflicts (Gardam and Charlesworth 2000; Gottschall 2004; Green 2004) and street violence (e.g. brawls, murders) as a component of civil wars and other conflicts.

In addition to the meta-level categories of protest and violence, WHIV includes political sanctions and relaxations. Sanctions include imposing restrictions (i.e. bans and martial law), censorship, covert monitoring, and political arrests. Relaxations includes demining, easing military blockades, relaxing curfews, releases and returns, relaxing censorship, releasing/returning persons and property, and relaxing administrative sanctions. Sanctions and relaxations are less common, with political arrests being the most common sanction, and return/release persons the most 
common relaxation. Note that natural language associates these with governments and/or organizations that claim governmental authority.

Actors/Targets. The actor/target list ranges from generic categories (e.g. state sector) to specific groups (e.g. Christians, Muslims, Kurds). Using the Wordnet dictionary (Fellbaum 2010), the machine coder identifies a particular event form as well as the actor and target of the event. Multiple events may come from the sentence. In $7.88 \%$ of WHIV events, the actor is missing and, in $10.01 \%$, the target. In news reportage, this is typical with some event forms (e.g. “A bomb exploded in a Sri Lankan market place today" provides no defined actor). ${ }^{7}$ The daily event file provides specific actors while in the annual file events are aggregated to broad sector actors: (1) all state actors (government agents, judiciary, national executive, military, police, diplomats, etc.); and (2) all civilian actors (insurgents, political parties, religious groups, farmers, business, bankers and financiers, journalists, etc.). This means that missing actor events (which are rare) are excluded in annual files. WHIV also includes "unknown state" and "unknown civilian" actors where the parser cannot assign a more specific actor due to limits of the text but the sector (e.g. "civilian," "state") is evident. "Unknown actors" include missing information and other grammatical expressions, such as physical objects (e.g. buildings, bridges) that cannot be identified as to specific social sector. ${ }^{8}$

Time. WHIV currently covers the period from January 1, 1990 to December 31, 2004. Event date is based on an assumed 24 hour clock day derived from either the news story text or the date line of the news story minus 1 day. This means that some events (e.g. multi-day protests) may generate a second or third, etc. daily event based on multi-day news reportage while others get just one reported event but may have in fact lasted multiple days. We clean all multiple reports of events within 24-hour daily units based on locations. This likely introduces 
little of an issue. As Francisco (2010: 79) reports for strikes, "the overwhelming majority last from 1 hour to 1 day." The same holds for the majority of protests, violence, political sanctions and relaxations, although it is important to recognize that some events (e.g. occupations, protest altruism) are often multi-day events (see Salehyan et al. 2012).

While most studies aggregate events to years or other larger time blocs, smaller time units are important for studying event processes, using, e.g. days (e.g. Khawaja 1993; Francisco 2009, 2010), weeks (Rasler 1996; Maher and Peterson 2007; Francisco 1996), months (Chang 2008), and quarters (Lee et al. 1996). Ultimately, the choice of appropriate time units is both theoretical (i.e. how long should a response involve?) and an empirical question (e.g. Shellman 2004; Freeman 1989).

Figures 1 and 2 provide a weekly aggregation of the global count of protest and violence (Figure 1), and a monthly aggregation of the global count of sanctions and relaxations in WHIV data (Figure 2). Violence displays greater volatility and higher counts, spiking upwards after the events of 9/11. Governmental sanctions and relaxations display greater trending. The count of relaxations is greater than sanctions, and has more spikes, particularly after 2003. While annual aggregation can be useful, Figures 1 and 2 show that aggregating also smooths what may be important temporal variation. This is an issue the analyst must make an empirically informed theoretical judgement about.

(Figure 1 and 2 about here)

Location. WHIV includes 231 countries, territories, and major world regions. Location is primarily determined by news information about the actor and target and, where unavailable as a second option, is inferred from the Reuters news report desk location. WHIV also includes specific territories that have been sites of contention (e.g. Corsica, Palestine, Northern Ireland) 
along with major world regions (e.g. "Southeast Asia") where no further information is provided about event location. It also contains transnational events (e.g. actor in Egypt, target in Libya). In the daily version of the data, location is identified separately for actor and for target. In the yearly data, location is based largely on the target characteristics based on the rationale that one knows where the, e.g. killing took place, even if you don't know who did it. If target location is not textually available, it is inferred from the actor location as a default. While the overwhelming majority of events are intra-state (i.e. locations of actor and target are identical), a growing share (roughly $5 \%$ ) of all events are transnational. ${ }^{9}$ The Israel-Palestinian conflict accounts for a third of these transnational events but, with that key conflict removed, there remains a slight uptick in transnational contention. One should recognize that newswires do not report location as a separate feature of events, meaning that we must rely on event and report desk reportage to infer location. This is in fact what all analysts relying on news reports rely upon.

(Figures 3 and 4 about here)

Figures 3 and 4 represent the average protest (Figure 3) and violence (Figure 4) per capita for the entire period. Protest per capita (Figure 3) is greatest in western democracies. In South America, Argentina, Suriname, French Guiana, Venezuela, and Uruguay have the highest rates of activity. In Africa, South Africa, Zimbabwe, Cote d'Ivorie, and Morocco top the list and, in Asia/Oceana, the Philippines, Afghanistan, Bhutan and Mongolia have the highest rates. Political violence (Figure 4) is significantly greater and more concentrated in countries that have experienced civil wars and international invasions (e.g. Iraq, Afghanistan, Algeria, Somalia, and former Yugoslavia states). Overall, rates of violence are much higher than rates of protest with peak figures between three and eighteen events per capita compared to between .25.and 1.9 
protest events per capita. Most likely this follows from the "newsworthiness" of violence over protest rather than its actual real-world incidence. Studies of news report bias have consistently found event intensity and, in particular, violence is an important factor in news selection. The distribution of protest and violence differ in notable ways that have the potential for fruitful comparative analysis, and, potentially, point to interesting comparative temporal patterns as well.

Reuters News Count- A key question is the size of the "newshole" that is generating contentious reports. Many analysts believe that this "newshole" is critical to allowing coverage of contentious events (e.g. Oliver and Maney 2000; Earl et. al 2003). Newswires are often thought to have a more flexible "newshole" but this should be tempered by awareness of the reporting capacities of newswire bureaus where a daily quota of reports is often a typical business constraint. To measure the "newshole," WHIV provides a count of the total of daily number of individual Reuters newstories by country-day which can be aggregated to the countryyear or other time unit. Thus, regardless of the number of contentious events, one can gauge the number of underlying news stories. This is derived from the larger IDEA dataset (King \& Lowe 2003). This provides some gauge of the Reuters reportage and a way of controlling for "newshole" effects on event reportage.

News Sources and Coding. As discussed, WHIV is auto-coded by the VRA Knowledge Manager ${ }^{\mathrm{TM}}$ parser, drawing on the first two full sentences of Reuters newswire stories. Beginning with the IDEA (King and Lowe 2003) dataset, we extracted all contentious events and cleaned the data for false positives, duplicates, and implausible events (e.g. weather "armed attacks"). The first cleaning step involved removing duplicate events generated by the parser for interstate conflict events. For instance, if the Israeli military conducted an aerial assault on a Palestinian insurgent, the parser would generate a second event that was identical in every way 
(event ID, etc.) with the exception that the countries were flipped (i.e. a Palestinian aerial assault on Israelis). We systematically cleaned these duplicate events by identifying cases where crossnational events were reciprocal and temporally and substantively identical.

After cleaning systematically produced duplicates, we evaluated whether actor/target combinations were plausible for each event form (i.e. is it plausible that a business takes other businesses hostage [HTAK] or engages in protest obstruction [POBS]? Or does this appear more likely to be metaphorical language used by news writers?). We identified questionable actor/target combinations, and then, with the help of a sample of event lead lines and operational information about the parser, we determined whether the actor/target combination was plausible for each event form. We removed events conducted by, targeting, or between specific groups for three broad reasons. The majority of cleaning focused on language confusion and illogical actors. These are events where the parser confuses turns of phrase for contentious events. Politicians "assaulting" opponents, businesses taking other businesses "hostage," etc, were removed. Additionally, despite the parser's attempts to omit them, a number of athletic events made it into the data, which we removed. In each of these cases, we reviewed several lead lines in order to ensure that we were not omitting any plausible events. For instance, the above example of businesses actors engaging in protest obstruction is a real example where angry Hungarian investors blocked traffic to protest government policies. We are not country experts, and so we did not review actor/target/event form pairings on a country by country basis. Instead, we left all plausible pairings in place, and so we encourage users to check the cleanliness of their data, particularly if they are conducting single country analysis. In sum, the cleaning process removed over 14 percent of all contentious IDEA events ( $6 \%$ were "false duplicates"). Internal reliability checks between computer and human coders offer further support. At its most refined level, we 
find positive intercoder reliability across the machine, three primary investigator coders, and four student coders (Krippendorf's Alpha=.68, CITE). When coder protocol was relaxed to a threedigit level, intercoder reliability improves considerably (Krippendorf's Alpha $=.88$ ) indicating that much of the inter-coder disagreement is over coding specificity and not across coded events. We explore these points of variability in more detail in a separate paper.

\section{Value Added}

The chief virtues of WHIV are its global coverage and comprehensive set of atomic contentious events. With daily data, one can aggregate to various time units and, by using actor, target and location, identify specific subsets of contentious interaction. By integrating WHIV events with IDEA events, one can construct conflict indices. Table 2 compares WHIV against other event datasets. All have particular advantages and can be combined for analysis. WHIV allows one to capture the strategic interaction between rival groups. This allows one to address questions such as when groups use particular types of contention, how contenders interact, and the escalation and de-escalation of conflict. Other conflict datasets have a different event focus (e.g. the onsets, duration and lethality of armed conflicts [Gleditsch et al. 2002), a narrower event framework (e.g. Raleigh et al. 2010; Banks and Wilson 2012]) or address a specific country or world region (e.g. Salehyan et. al, 2012). The newly released GDELT dataset (Leetaru \& Schrodt 2013) has the advantages of the broad CAMEO event framework, multiple news sources (Googlenews) and subnational geo-referencing but, as of yet, does not provide a way to separate out the simple growth of international news reportage from actual fluctuations in contentious events. Other international event data projects, such as the World-wide Integrated Crisis Warning System (ICEWS ${ }^{10}$ and the Phoenix Data Project ${ }^{11}$ have developed highly sophisticated programs for integrating hundreds of diverse sources (newswires, online papers, blogs, etc.) to 
construct event data and are beginning to release their data for secondary analysis. There are complexities with addressing news selection with these multisource products (Jenkins and Maher 2016) but they indicate the direction of future international event data development.

(Table 2 about here)

\section{Conclusion}

WHIV provides a unique opportunity for the study of contentious interactions between contending groups in a global cross-national context. It builds on a machine coding system that has been shown to be as accurate as human coding (King \& Lowe 2003) and involves additional cleaning for duplicates, false positives and other errors that further improve its accuracy and recall. It strengthens our ability to study low-intensity conflict, strategic interaction between contenders, processes of escalation and de-escalation, the effect of contention on political and social change and a range of similar issues.

We envision a number of uses for the WHIV dataset by the social science community. The most obvious use is for global comparative analysis of political processes. To date, comparative analyses of dissent, repression, and intra-state conflict have had to choose between limited geographic variability (Rasler 1996; Moore 1998), limited variability in regards to event forms, and limited temporal variability (Davenport 1995; Carey 2010; Ortiz 2007). The availability of WHIV opens opportunities for more detailed analyses of contentious processes, and more rigorous hypothesis testing. Additionally, the detailed nature allows for improved modeling and testing of conflict escalation processes. Evaluating how changes in dissent and repression tactics (Lichbach 1987) happens at the daily, weekly, or monthly level, as well as how these processes vary across countries and regions offers a more fine-grained lens for evaluating how both war and peace breakout. WHIV also includes several unique event forms (e.g. sexual 
assaults, street assaults) which have been neglected in event analysis. Finally, we envision that this dataset will be useful for scholars interested in using contentiousness as an independent variable for analyses of a variety of processes. The level of contentious state has an obvious impact on economic development, fiscal crises, democratization, and how protest and violence influence political access and corruption. Scholars may also be interested in the relationship between norm diffusion and state behavior. There are a number of additional potential uses of the WHIV data, and we hope that scholars find it a useful tool for pushing the field of international conflict forward. 


\section{References}

Banks, Arthur S. and Kenneth A. Wilson. 2012. "Cross-National Time-Series Data Archive." Retrieved (http://www.databanksinternational.com).

Barrie, Christopher and Neil Ketchley. 2018. "Opportunity without Organization: Labour Mobilization in Egypt after the $25^{\text {th }}$ January Revolution.” Mobilization https://papers.ssrn.com/sol3/papers.cfm?abstract_id=2997517

Bernauer, Thomas et al. 2012. "Water-Related Intrastate Conflict and Cooperation (WARICC): A New Event Dataset.” International Interactions 38(4):529-45.

Bernauer, Thomas and Nils Petter Gleditsch. 2012. New Event Data in Conflict Research. Taylor \& Francis.

Bond, Doug, Joe Bond, Churl Oh, J. Craig Jenkins, and Charles Lewis Taylor. 2003. "Integrated Data for Events Analysis (IDEA): An Event Typology for Automated Events Data Development." Journal of Peace Research 40(6):733-745.

Costello, Matthew. 2018. "Oil and Gas Rents and Civilian Violence in the Middle East and North Africa, 1990-2004: Resource Curse or Rentier Peace?” Social Sciences 7(3); doi:10.3390/socsci7030039.

DeMerritt, Jacqueline Hope Rubin. 2009. Delegating Death: A Strategic Logic of Governmental Killing. PhD Dissertation, Florida State University.

Eck, Kristine and Lisa Hultman. 2007. “One-Sided Violence against Civilians in War: Insights from New Fatality Data.” Journal of Peace Research 44(2):233-246.

Galster, Kirk. 2015. "Poverty and Conflict: Can Economic Development Prevent Conflict?" Journal of Interdisciplinary Conflict Science I:1-35. 
https://nsuworks.nova.edu/cgi/viewcontent.cgi?referer=https://scholar.google.com/\&https redir $=1 \&$ article $=1000 \&$ context $=$ jics

Gardam, Judith Gail and Hilary Charlesworth. 2000. "Protection of Women in Armed Conflict." Human Rights Quarterly 22(1):148-166.

Gerner, Deborah J., Philip A. Schrodt, Ronald A. Francisco, and Judith L. Weddle. 1994.

"Machine Coding of Event Data Using Regional and International Sources." International Studies Quarterly 91-119.

Gilley, Bruce. 2006. "The Meaning and Measure of State Legitimacy.” European Journal of Political Research 45:499-525.

Gilmore, Elisabeth, Nils Petter Gleditsch, Päivi Lujala, and Jan Ketil Rød. 2005. "Conflict Diamonds: A New Dataset." Conflict Management and Peace Science 22(3):257-272.

Gleditsch, Nils Petter, Peter Wallensteen, Mikael Eriksson, Margareta Sollenberg, and H\a avard Strand. 2002. “Armed Conflict 1946-2001: A New Dataset.” Journal of Peace Research 39(5):615-637.

Goldstein, Joshua S. 1992. “A Conflict-Cooperation Scale for WEIS Events Data.” Journal of Conflict Resolution 36(2):369-385.

Gottschall, Jonathan. 2004. “Explaining Wartime Rape.” Journal of Sex Research 41(2):129136.

Green, Jennifer L. 2004. “Uncovering Collective Rape: A Comparative Study of Political Sexual Violence.” International Journal of Sociology 34(1):97-116.

Hanna, Alex. 2016. Automated Coding of Protst Event Data: Development and Applications. PhD Dissertation. University of Wisconsin-Madison. 
Jenkins, J. Craig and Doug Bond. 2001. "Conflict-Carrying Capacity, Political Crisis, and Reconstruction A Framework for the Early Warning of Political System Vulnerability.” Journal of Conflict Resolution 45(1):3-31.

Jenkins, J. Craig and Matthew Costello. 2018. “Oil States, State Capacity and Rebellion: Does Oil Breed or Contain Rebellious Violence.” Dept of Sociology, Ohio State University. Kadivar, Mohammad Ali and Neal Caren. 2015. "Disruptive Democratization: Contentious Events and Liberalizing Outcomes Globally, 1990-2004.” Social Forces 94(3):975-996.

Kadivar, Mohammad Ali, Adaner Usmani, Benjamin Bradlow. 2017. "The Long March: Contentious Mobilization and Deep Democracy.” Research Paper \#2017-38. Watson Institute for International and Public Affairs, Brown University.

Kadivar, Mohammad Ali and Neil Ketchley. 2018. "Sticks, Stones and Molotov Cocktails: Unarmed Collective Violence and Democratization.” Watson Institute for International and Public Affairs, Brown University.

Linke, Andrew M., Frank D. W. Witmer, and John O’Loughlin. 2012. "Space-Time Granger Analysis of the War in Iraq: A Study of Coalition and Insurgent Action-Reaction.” International Interactions 38(4):402-25.

Loyle, Cyanne E., Christopher Sullivan, and Christian Davenport. 2014. "The Northern Ireland Research Initiative: Data on the Troubles from 1968 to 1998." Conflict Management and Peace Science 31(1):94-106.

McClelland, Charles A. and Gary D. Hoggard. 1969. "Conflict Patterns in the Interactions Among Nations.” Pp. 711-24 in International Politics and Foreign Policy: A Reader in Research and Theory, edited by J. N. Rosenau. New York: Free Press. 
O’Brien, Sean P. 2010. “Crisis Early Warning and Decision Support: Contemporary Approaches and Thoughts on Future Research." International Studies Review 12(1):87-104.

Raleigh, Clionadh, Andrew Linke, Haavard Hegre, and Joakim Karlsen. 2010. “Introducing ACLED: An Armed Conflict Location and Event Dataset." Journal of Peace Research 47(5):651-660.

Rasler, Karen. 1996. "Concessions, Repression, and Political Protest in the Iranian Revolution." American Sociological Review 132-152.

Rod, Espen Geelmuyden and Nils G. Weidmann. 2013. "Protesting Dictatorship: The Mass Mobilization in Autocracies Database." http://citeseerx.ist.psu.edu/viewdoc/download?doi=10.1.1.716.2625\&rep=rep1\&type=pdf

Salehyan, Idean et al. 2012. "Social Conflict in Africa: A New Database." International Interactions 38(4):503-511.

Schneider, Gerald, Margit Bussmann, and Constantin Ruhe. 2012. "The Dynamics of Mass Killings: Testing Time-Series Models of One-Sided Violence in the Bosnian Civil War.” International Interactions 38(4):443-461.

Schrodt, Phil A. 2012. "Precedents, Progress, and Prospects in Political Event Data." International Interactions 38(4):546-569.

Schrodt, Philip A. and Deborah J. Gerner. 1994. "Validity Assessment of a Machine-Coded Event Data Set for the Middle East, 1982-92.” American Journal of Political Science $825-854$.

Sirkeci, Ifran and Jerry Cohen. 2016. "Cultures of Migration and Conflict in Contemporary Human Mobility in Turkey.” European Review 24(3):381-396. 
Shellman, Stephen M. 2004. “Time Series Intervals and Statistical Inference: The Effects of Temporal Aggregation on Event Data Analysis.” Political Analysis 12(1):97-104. Sullivan, Christopher M., Cyanne E. Loyle, and Christian Davenport. 2012. "The Coercive Weight of the Past: Temporal Dependence and the Conflict-Repression Nexus in the Northern Ireland 'Troubles.'” International Interactions 38(4):426-442.

Tarrow, Sidney. 2004. Power and Movement. New York: Cambridge University Press.

Taylor, Charles L. and David Jodice. 1983. "World Handbook of Social and Political Indicators." New Haven.

Underwood, Patrick. 2016. Conflict and Stability in the Neoliberal Era: Explaining Urban Unrest in Latin America. PhD Dissertation. Seattle: University of Washington.

Urdal, Henrik and Kristian Hoelscher. 2012. "Explaining Urban Social Disorder and Violence: An Empirical Study of Event Data from Asian and Sub-Saharan African Cities." International Interactions 38(4):512-528.

Wada, Takeshi. 2016. "Rigidity and Flexibility in the Repertoires of Contention." Mobilization 21(4):449-468.

Wilkenfeld, Jonathan, Michael Brecher, Joseph Hewitt, Kyle Beardsley, and Pelin Eralp. 2010. “International Crisis Behavior Dataset: Version 10 (1918-2007)." Center for International Development and Conflict Management. Retrieved (http://www.cidcm.umd.edu/icb/data/). 


\begin{tabular}{|c|c|c|c|c|c|}
\hline \multirow{2}{*}{\multicolumn{2}{|c|}{ Event form \& category name }} & \multirow{2}{*}{$\begin{array}{c}\text { Daily File } \\
\text { Frequency } \\
\end{array}$} & \multicolumn{3}{|c|}{ Annual File } \\
\hline & & & Mean & Min & Max \\
\hline \multicolumn{6}{|c|}{ Protest } \\
\hline PDEM & Protest demonstration & 8,884 & 0.79 & 0 & 76 \\
\hline PALT & Protest altruism & 1,122 & 0.1 & 0 & 18 \\
\hline PMAR & Protest procession & 4,325 & 0.384 & 0 & 47 \\
\hline POBS & Protest obstruction & 2,980 & 0.265 & 0 & 21 \\
\hline PPRO & Protest defacement & 1,745 & 0.155 & 0 & 19 \\
\hline SRAL & Rally support & 20,439 & 1.817 & 0 & 348 \\
\hline STRI & Strikes \& boycotts & 15,547 & 1.382 & 0 & 114 \\
\hline \multicolumn{6}{|l|}{ Violence } \\
\hline ABDU & Abduction & 222 & 0.02 & 0 & 8 \\
\hline HTAK & Hostage taking & 5,825 & 0.517 & 0 & 61 \\
\hline JACK & Hijacking & 917 & 0.082 & 0 & 20 \\
\hline CBRU & WMD attack & 16 & 0.001 & 0 & 3 \\
\hline $\mathrm{CBIO}$ & Chem/bio attack & 121 & 0.011 & 0 & 6 \\
\hline PASS & Physical assault & 52,015 & 4.62 & 0 & 597 \\
\hline BEAT & Beating & 1,485 & 0.132 & 0 & 42 \\
\hline CORP & Corporal punishment & 2,846 & 0.253 & 0 & 57 \\
\hline SEXA & Sexual assault & 316 & 0.028 & 0 & 10 \\
\hline MAIM & Torture & 1,374 & 0.122 & 0 & 19 \\
\hline RAID & Armed action & 35,873 & 3.182 & 0 & 403 \\
\hline AERI & Missile attack & 7,799 & 0.691 & 0 & 223 \\
\hline ASSA & Assassination & 1,925 & 0.171 & 0 & 31 \\
\hline $\mathrm{CONC}$ & Crowd control & 4,775 & 0.424 & 0 & 50 \\
\hline COUP & Coups \& mutinies & 718 & 0.064 & 0 & 18 \\
\hline GRPG & Artillery attack & 16,724 & 1.486 & 0 & 672 \\
\hline MINE & Mine explosion & 1,179 & 0.105 & 0 & 70 \\
\hline PEXE & Small arms attack & 36,613 & 3.251 & 0 & 401 \\
\hline SBOM & Suicide bombing & 1,331 & 0.118 & 0 & 191 \\
\hline VBOM & Vehicle bombing & 1,739 & 0.155 & 0 & 273 \\
\hline RIOT & Riot & 2,856 & 0.254 & 0 & 45 \\
\hline \multicolumn{6}{|l|}{ Sanction } \\
\hline BANA & Impose restriction & 3,843 & 0.342 & 0 & 39 \\
\hline CENS & Censorship & 1,292 & 0.115 & 0 & 25 \\
\hline MONI & Covert monitoring & 1,547 & 0.138 & 0 & 32 \\
\hline POAR & Political arrest & 8,108 & 0.721 & 0 & 72 \\
\hline \multicolumn{6}{|l|}{ Relaxation } \\
\hline DMIN & Demining & 489 & 0.043 & 0 & 10 \\
\hline EMSA & Ease military blockade & 146 & 0.013 & 0 & 8 \\
\hline RCUR & Relax curfew & 278 & 0.025 & 0 & 8 \\
\hline RELE & Release/return & 2,313 & 0.206 & 0 & 42 \\
\hline RRPE & Release/return persons & 12,976 & 1.153 & 0 & 114 \\
\hline RRPR & Release/return property & 1,175 & 0.104 & 0 & 11 \\
\hline RPOL & Relax censorship & 104 & 0.009 & 0 & 4 \\
\hline RSAN & Relax admin. sanction & 307 & 0.027 & 0 & 9 \\
\hline
\end{tabular}


Figure 1: Global Protest and Violence by Week, 1990-2004

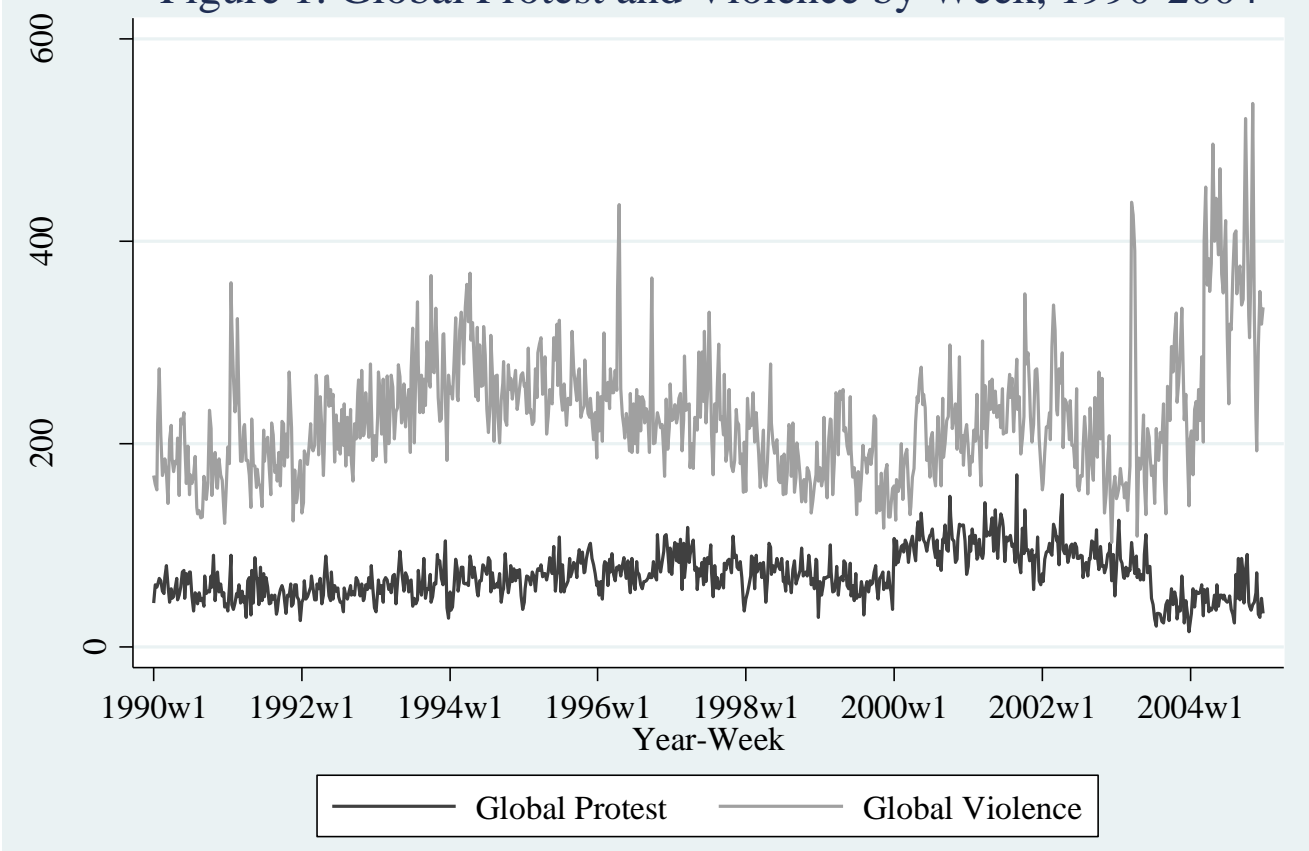

4

Figure 2: Global Sanction and Relaxation by Month, 1990-2004

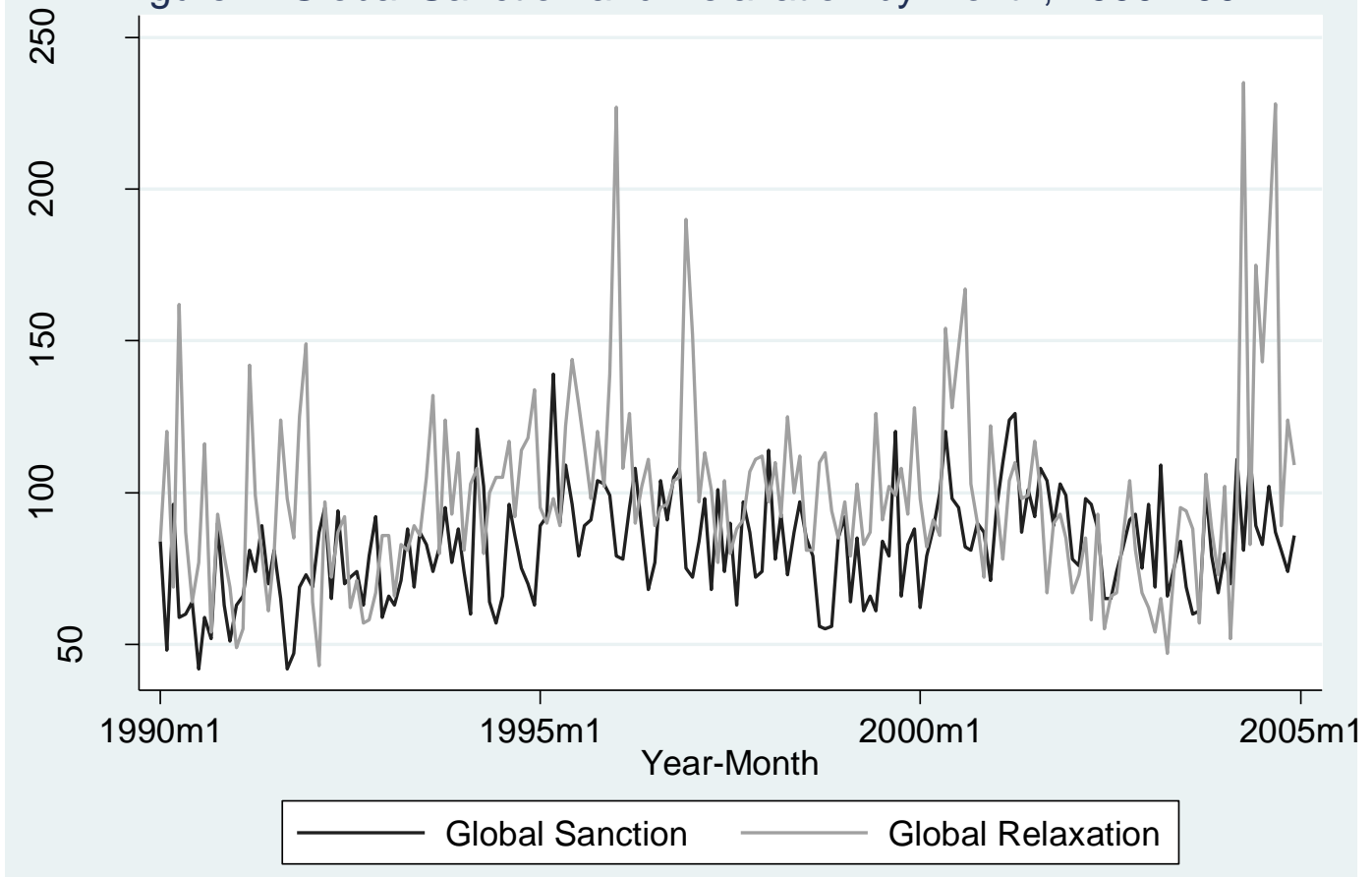


WHIV Political Protest Events per Capita, 1990-2004

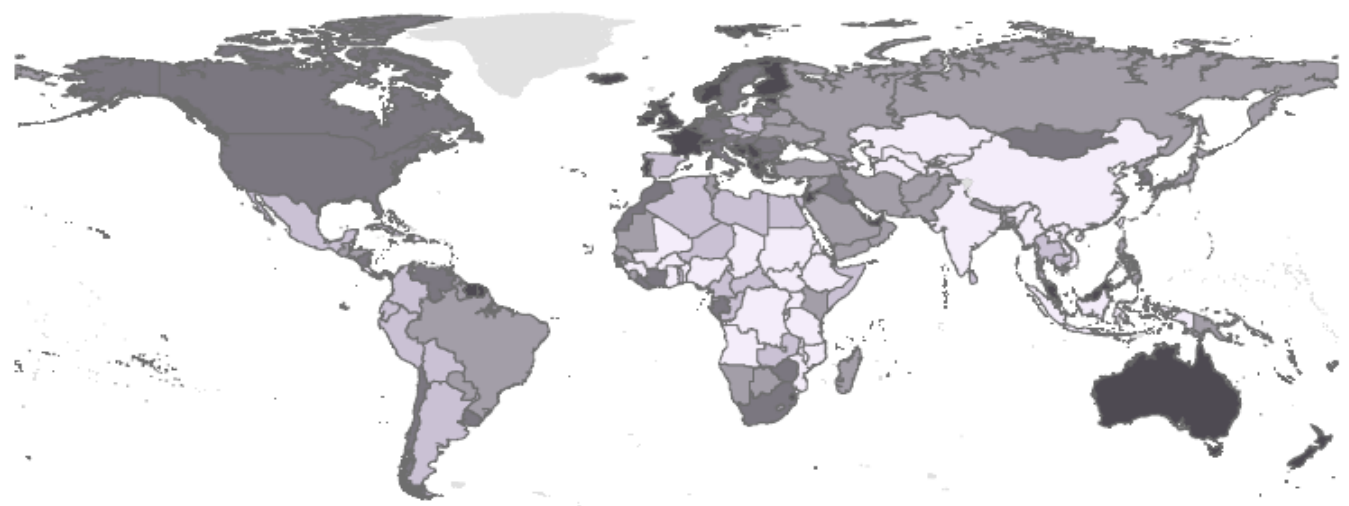

\section{Legend}

Political Protest per Capita missing or no pop. data $.00-.03$ events per capita $.03-.06$ events per capita
$.06-.10$ events per capita

$.10-.25$ events per capita $.25-1.9$ events per capita

Figure 3: WHIV Protest Events per Capita, 1990-2004 


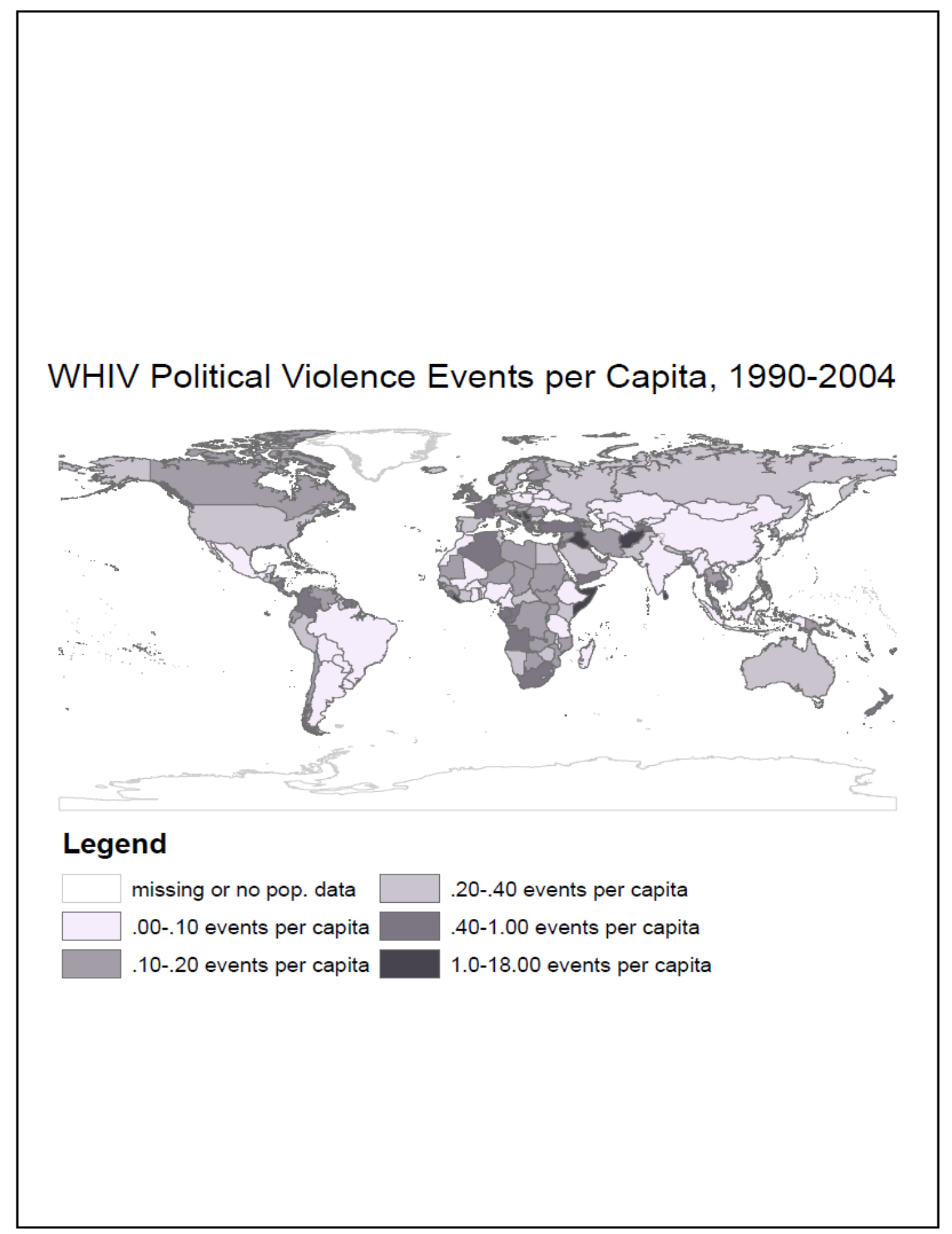

Figure 4: WHIV Violence Events per Capita, 1990-2004 
Table 2: Selected Publicly Available Conflict Data Sets.

\begin{tabular}{|c|c|c|c|c|c|c|c|c|}
\hline Dataset & $\begin{array}{c}\text { Year } \\
\text { Coverage }\end{array}$ & $\begin{array}{l}\text { Geographic } \\
\text { Coverage }\end{array}$ & $\begin{array}{l}\text { Event Data } \\
\text { Type }\end{array}$ & $\begin{array}{l}\text { Major Event } \\
\text { Types }\end{array}$ & $\begin{array}{l}\text { \# of Event } \\
\text { Forms }\end{array}$ & $\begin{array}{l}\text { Information } \\
\text { Source }\end{array}$ & $\begin{array}{c}\text { Geo- } \\
\text { Referenced? }\end{array}$ & Citation \\
\hline $\begin{array}{l}\text { World Handbook } \\
\text { of Political } \\
\text { Indicators IV }\end{array}$ & $1990-2004$ & Global & Discrete & $\begin{array}{l}\text { Protest, political } \\
\text { violence, } \\
\text { sanctions, and } \\
\text { relaxations }\end{array}$ & 40 & $\begin{array}{l}\text { Reuters } \\
\text { Newswire }\end{array}$ & No & $\begin{array}{l}\text { Jenkins, Taylor, } \\
\text { Abbott, Maher, and } \\
\text { Peterson } 2012\end{array}$ \\
\hline $\begin{array}{l}\text { UCDP/PRIO- } \\
\text { Uppsala Armed } \\
\text { Conflict v.4 }\end{array}$ & $1946-2011$ & Global & Episode & $\begin{array}{l}\text { Intra and inter } \\
\text { state conflict }\end{array}$ & 4 & $\begin{array}{l}\text { Multi-Source } \\
\text { (Factiva } \\
\text { Online) }\end{array}$ & No & $\begin{array}{l}\text { Gleditsch, Wallensteen, } \\
\text { Eriksson, Sollenberg, } \\
\text { and Strand } 2002\end{array}$ \\
\hline ACLED & $1997-2011$ & Africa & Process & $\begin{array}{l}\text { Battles, base } \\
\text { establishments, } \\
\text { rioting/protesting, } \\
\text { and violence }\end{array}$ & 6 & $\begin{array}{l}\text { Multi-Source } \\
\text { (IRIN, Factiva, } \\
\text { etc.) }\end{array}$ & Yes & $\begin{array}{l}\text { Raleigh, Linke, Hegre, } \\
\text { and Karlsen, } 2010\end{array}$ \\
\hline SCAD & $1990-2011$ & Africa & Process & $\begin{array}{l}\text { Demonstrations, } \\
\text { riots, strikes, and } \\
\text { violence }\end{array}$ & 5 & $\begin{array}{c}\text { Associated } \\
\text { Press and } \\
\text { Agence France } \\
\text { Press }\end{array}$ & Yes & $\begin{array}{l}\text { Salehyan, Hendrix, } \\
\text { Case, Linebarger, Stull, } \\
\text { and Williams. } 2012\end{array}$ \\
\hline KEDS & $1979-2011$ & Regional & Discrete & $\begin{array}{c}\text { International } \\
\text { political event } \\
\text { data }\end{array}$ & 235 & $\begin{array}{l}\text { Reuters/AFP } \\
\text { Newswire }\end{array}$ & No & $\begin{array}{l}\text { Schrodt and Gerner, } \\
2010\end{array}$ \\
\hline GDELT & $1979-2013$ & Global & Discrete & $\begin{array}{l}\text { Intl. political } \\
\text { event data }\end{array}$ & 235 & $\begin{array}{l}\text { Multi-source } \\
\text { (AFP, Google } \\
\text { News) }\end{array}$ & Yes & $\begin{array}{l}\text { Leetaru and Schrodt, } \\
2013\end{array}$ \\
\hline $\begin{array}{l}\text { Cross National } \\
\text { Time Series } \\
\text { (Banks) }\end{array}$ & 1919-2011 & Global & $\begin{array}{c}\text { Annual } \\
\text { Count }\end{array}$ & $\begin{array}{l}\text { Domestic } \\
\text { Conflict }\end{array}$ & 8 & Unknown & No & $\begin{array}{l}\text { Banks and Wilson, } \\
2012\end{array}$ \\
\hline PRODAT & $1950-2002$ & Germany & Discrete & Protest & 22 & $\begin{array}{c}\text { Frankfurter } \\
\text { Rundschau and } \\
\text { Süddeutsche } \\
\text { Zeitung }\end{array}$ & No & Rucht and Teune, 2002 \\
\hline YANKDAT & 1960-1995 & $\begin{array}{l}\text { United } \\
\text { States }\end{array}$ & Discrete & Protest & 21 & $\begin{array}{l}\text { New York } \\
\text { Times }\end{array}$ & No & $\begin{array}{l}\text { McAdam, McCarthy, } \\
\text { Olzak, and Soule, } 2010\end{array}$ \\
\hline
\end{tabular}


${ }^{1}$ IDEA overlaps with the CAMEO event framework with a small number of event form and actor/target exceptions.

${ }^{2}$ For other comprehensive global and regional events data sets that address similar event forms, see the Integrated Crisis Early Warning System (ICEWS) (https://dataverse.harvard.edu/dataverse/icews), the Social Conflict Analysis Database (SCAD) (https://www.strausscenter.org/scad.html), and the Armed Conflict Location and Event Data Project (ACLED) ( https://www.acleddata.com/). Each project has its own unique advantages in terms of event coverage, time and country/regional coverage along with distinct methodology of construction.

${ }^{3}$ In this sense, it is most comparable to ICEWS, which has the advantage of multi-source coding and coverage of both contentious and non-contentious event forms.

${ }^{4}$ Other event data projects such as ACLED and ICEWS have more fine-grained geocoding. 5 The original IDEA data, also known as King and Lowe data, is available through their Dataverse site (http://gking.harvard.edu/data?dvn_subpage=/faces/study/StudyPage.xhtml?globalId=hdl:1902.1 (FYXLAWZRIA). WHIV is a subset of this data that has been cleaned for non-events, false positives, and other errors. For further questions about the comparison between King/Lowe data and WHIV, please see the FAQ page on the WHIV website.

${ }^{6}$ Definitions for each of the event forms can be found in the codebook (available at https://sociology.osu.edu/worldhandbook).

${ }^{7}$ An expert can of course make reliable attributions as to the identity of such actors, which can be done in customized uses of WHIV data. 
${ }^{8}$ Due to copywrite limitations, we cannot provide the literal texts of these actors and targets, making it impossible to make educated attributions as to the identity of these actors and targets. ${ }^{9}$ All state to state war events conducted by government actors and targeting government actors are excluded from the WHIV dataset.

${ }^{10}$ ICEWS; http://www.lockheedmartin.com/us/products/W-ICEWS/W-ICEWS_overview.html

${ }^{11}$ http://phoenixdata.org 